\title{
Exploring Parent-Teacher Partnerships as Border Pedagogy: Supporting Emergent Bilingual Student Learning
}

\author{
Sandra Mercuri \\ The University of Texas Rio Grande Valley \\ Texas, USA
}

\begin{abstract}
Developed by a bilingual teacher educator in the U.S. working with in-service teachers serving predominantly bilingual students from U.S. and Mexico, this study is uniquely positioned to use innovative research in bilingual teacher education for empowering teachers to develop culturally and linguistically responsive border pedagogies. Specifically, this study explores parent-teacher partnerships as border pedagogy that supports emergent bilingual student teaching and learning. Aimed at disrupting traditional modes of research and practice grounded in monolingualism, this qualitative critical study uses the concept of border pedagogy as a theoretical framework to explore how 16 bilingual in-service teachers enrolled in a master's program engaged in parent-teacher partnerships that supported bilingual and bicultural teaching and learning at the U.S.-Mexico border.
\end{abstract}

\section{Bilingual Education and the U.S.-Mexico Border}

The U.S.-Mexico border is a binational, bicultural, and bilingual space where social, economic and political boundaries exemplified in the border wall divide people who share the same cultural and linguistic space. The border is also a historical and geographical space of cultural and linguistic fluidity, reflected in the diverse families and communities living at the border. No specific definition fits the norm for a border family, as U.S. Americans; Mexicans; U.S. citizens of Mexican descent; Hispanics; Latinos; intercultural marriages of couples split between either side of the border; temporary migrants from Mexico and South America; documented and undocumented immigrants; undocumented immigrant parents with U.S. American-born children; siblings in the same family who are below eighteen years of age with some who are legal and others who are not; families with one parent legal, the other illegal; single-parent families; parents in border detention facilities; children raised by migrant communities in the absence of parents; and families at various intersections of languages, 
cultures, communities, and countries coexist on the U.S. side of the 1969-mile border wall (Romo \& Chavez, 2006). This juxtaposition of social, economic, and political boundaries with cultural fluidity complicates fixed notions of race, ethnic, and linguistic identities reflected in educational issues that are unique to the border.

In this unique border site, the student population in K-12 and higher education is a complex and dynamic mix of predominantly Spanish-speaking populations consisting of bilingual fluent speakers of Spanish and English, those in the process of acquiring English as a second language as emergent bilinguals, and monolingual speakers of Spanish, with a few exceptions who are monolingual speakers of English. The U.S.-Mexico border reflects the national trend of a growing number of English language learners (ELLs) in public schools across the U.S. who speak Spanish, perform below grade level in school and standardized tests, and drop out of school at a higher rate than their English-proficient peers (García \& Cuellar, 2006). Most Spanish-speaking ELLs come from low socioeconomic backgrounds, and their parents and families have lower levels of education than their monolingual, English-proficient peers, and many do not speak or read any level of English (Zong \& Batalova, 2015). Schools with a high ELL population in their classrooms document the challenges of parental involvement (Arias \& Morillo-Campbell, 2008), communication gaps between teachers and parents, and a lack of research-based resources and strategies needed to teach ELLs. On the other hand, parents of ELLs committed to their children's education feel alienated from school processes, do not connect with teacher expectations, and experience exclusion from the very schools their children attend (Gandara, Maxwell-Jolly, \& Driscoll, 2005).

According to research, most teachers who are White and monolingual experience challenges when teaching students from cultural and linguistic backgrounds different from their own (Garza, 2007). Research documents that many monolingual teachers view emergent bilingual students from a deficit perspective, attributing low academic performance to academic deficiency and cultural inadequacy (Garcia, Kleifgen \& Falchi, 2008). According to Garcia et al., deficit thinking explains school failure as an outcome of cultural inadequacy, a perspective that is prevalent among teachers whose culture differs from students' backgrounds. Less documented is the reality that similar perspectives persist among many bilingual Spanish-English speaking teachers at the border who have internalized dominant worldviews and view emergent bilingual students (EBs) as culturally and linguistically deficit (Piedra, 2007). In my professional experience at the U.S.-Mexico border, in spite of sharing similar cultural and linguistic backgrounds with their students, many bilingual teachers claim to endorse Spanish as an asset to learning; however, their classroom pedagogies reflect deficit views of low-income Mexican origin and Mexican immigrant students, families, and communities.

As a Spanish-speaking immigrant and bilingual teacher educator at a public university in the United States located at the U.S.-Mexico border, I recognize this gap between teachers and their culturally and linguistically diverse students, parents, and communities and the challenges on both sides in bridging the gap. Research documents that one approach to bridging the gap between teachers and students is to prepare linguistically responsive teachers with the knowledge, skills, and dispositions for teaching the growing numbers of ELLs, henceforth addressed as Emergent Bilingual students (EBs), across public schools in the U.S. Rather than ELLs, I have chosen to use the term EBs for English language learners who are emergent bilinguals, being proficient in their home language and in the process of acquiring proficiency in English, their new language of schooling (Garcia, et al., 2008). According to Garcia et al., historically, the term ELL emerges from a deficit perspective, implying that students who are in 
the process of acquiring English as their second language bring with them a cultural and linguistic deficiency that is difficult to overcome. In policy and school discourse, the term denotes a deficit that stigmatizes students; therefore, I use the term EBs to denote the complex cultural, linguistic, and literacy skills that students proficient in their home language and learning a second language bring into the classroom.

As faculty in a bilingual education and bicultural studies program, I teach undergraduate courses to preservice teachers working toward a Texas teacher certification; graduate courses in bilingual education to in-service teachers from public schools serving predominantly bi-national, bilingual and bicultural students; and courses with doctoral students who are school administrators and curriculum and reading specialists in school districts from several border towns of south Texas. Some of my students in all levels of the program commute from Mexico on a daily basis. Working out of this particular context, my teaching and research consist of border pedagogies focused on promoting bilingual education, preparing teachers and administrators with competencies for responding to cultural and linguistic diversity, and developing inclusive multicultural pedagogies for serving the academic needs of students, parents, and communities at the U.S.-Mexico border.

In response to the critical need for bridging the gap between teachers on the one hand, and EBs and their parents and communities on the other, this article reports on research that examines how bilingual ESL classroom teachers engage in parent-teacher partnerships to reconceptualize their teacher roles by becoming advocates of emergent bilingual students through complex border pedagogies in bicultural and bilingual contexts. For the purpose of this article, I use the term "border pedagogy" as a process of disrupting dominant forms of educational and institutional knowledge that define and reproduce social relations of power and privilege; as a means for understanding teaching and learning as geographically, historically, and politically situated in specific contexts that are binational, bicultural and bilingual; and as a set of multicultural competencies for including the histories and experiences of students, parents, and local communities in school curricula as knowledge that counts (Garza, 2007). In what follows, I review literature organized around three key interrelated themes in teacher education: bilingual education, culturally and linguistically responsive pedagogy, and parent-teacher partnership for student success.

\section{Literature Review}

Research advocates pedagogies responsive to students' cultures, languages, and lived experiences in order to close the achievement gap in education (Nieto, 2004); however, my own experiences working at the border indicate many teacher education students, public school teachers and administrators, and teacher educators resist the predominant presence of Mexican culture, the use of Spanish as the preferred language of communication, and discount the use of bilingual forms of literacy in and out of school. State-mandated school language policies and teachers' classroom pedagogies continue to institutionalize monolingual pedagogies in design and implementation that limit teachers' capacities and dispositions for working with bicultural and transnational students (Cline \& Necochea, 2006). As a way of disrupting deficit perspectives, teacher education programs along the border recommend infusing teacher preparation curriculum with opportunities for future teachers to understand and reflect on the critical link between teachers' pedagogical knowledge and attitudes toward cultural and linguistic diversity (Guerrero \& Valadez, 2011). Guerrero and Valadez advocate the use of 
historical, cultural, and linguistic backgrounds of their students, families, and communities as building blocks for developing pedagogies relevant to the historical and geographical context of the border.

While accreditation standards and teacher competencies emphasize teaching for diversity and collaborating with parents and communities, research shows that many classroom teachers, both monolingual and bilingual, do not have preparation to provide high-quality instruction to an increasing population of students from diverse language backgrounds (Ballantyne, Sanderman \& Levy, 2008). Research also shows many schools systematically devalue the socio-cultural backgrounds and language and literacy practices of students who are culturally and linguistically diverse and who do not identify with the dominant culture of public education (Valenzuela, 1999). When dominant cultural values are endorsed in schools or when diverse cultures, languages, and experiences are excluded from the curriculum, culture becomes a form of social and academic capital that schools use to privilege and exclude (Bedolla, 2005). This form of cultural capital constitutes cultural background, knowledge, skills, language, socio-economic status as well as perspectives, attitudes, and beliefs used as a form of social capital in everyday interactions (Bourdieu, 1986). Working-class students who are able to socialize into dominant worldviews gain social and cultural capital from middle-class peers and adults in institutional contexts through strategic positioning such as advanced placement classes, extracurricular activities, and school appointments (Gándara, 2011).

Relations between students, parents, and communities on the one hand, and school personnel, teachers, and peers on the other play a key role in socializing students from diverse family backgrounds and languages into the educational system's ideological foundation (Coleman \& Hoffer, 1987). Students who are able to socialize through such relationships build educational capital for academic success, while those who resist or are unable to give up their home cultures and languages find themselves excluded from school processes (Stanton-Salazar, 2004). Within current contexts of U.S. American education, getting an education implies knowing the processes of learning as well as the symbolic representations of the dominant culture in which students and teachers are socialized or marginalized (Auerbach, 2009). For many EBs and their families, schooling becomes a site for struggle where cultural knowledge, language skills, and multiple worldviews - the very terms of education - are being mediated and negotiated on a daily basis.

With the demographic shift in student populations in K-12 public schools, DarlingHammond and Bransford (2005) note that engaging diverse students' families in educational processes has the potential for improving academic outcomes. However, immigrant and binational parents and families of EBs at the U.S.-Mexico border face particular barriers to becoming actively involved in their children's schooling. Lack of economic capital, working multiple jobs with economic consequences for missing work, temporary residency as migrant workers, legality of their complex and fluid immigration status, gaps in cultural knowledge, communication and language barriers on both sides, deficit perspectives of teachers, and a general sense of rejection from the school community are some of the challenges that parents encounter in the education system (Ariza, 2010).

Therefore it is essential to develop new and inclusive approaches that make the knowledge and experiences of EBs, parents, and families count within the school (Houk, 2005). According to research, teachers who include cultural and family knowledge in the curriculum, respond to the needs of students and their families, and build partnerships with parents provide more opportunities for emergent bilingual students' academic success (Arias \& Morillo- 
Campbell, 2008). It is critical for all educators, including those who are bilingual, to acquire a strong knowledge base of the unique historical, cultural, and linguistic backgrounds of students and their families and include parents in school processes to enhance students' opportunities for academic success (Guerrero \&Valadez, 2011). Teachers with multicultural competencies ground their curricula in border pedagogies that validate the bicultures and biliteracies of students, families, and communities through strong community partnerships (Rodriguez \& Mercuri, 2013).

The above literature review evidences there is a critical need for schools to foster parental involvement by developing culturally and linguistically responsive ways to include students, parents, and families as partners in education so that EBs, including those at the U.S.-Mexico border, experience inclusive education and equitable opportunities for academic success. Exploring parent-teacher partnerships at the border, in the next section, I outline the theoretical framework that supports this study.

\section{Border Pedagogy as a Theoretical Framework}

According to Reyes (2005), border pedagogy is a "set of multifaceted, complex, and interactive factors; educational policies; curriculum; instructional practices; and a knowledge base that educators need to consider to increase the academic achievement of diverse students in the border region" (p. 149). Border pedagogy is a response to the need for better "school systems and structures, that are more equitable and just, that understand the extreme complexity of the borderland experience and implement instructional practices that are more teacher driven and contextually based" (Cline \& Necochea, 2003, p. 46). Border pedagogy responds to cultural and linguistic diversity on many levels.

First, border pedagogies recognize that the border between the U.S. and Mexico is a geographical, historical, and binational region that brings together communities on the one hand, and a cultural, social, and political space that divides communities, on the other (Estrada, 2006). Second, in this socioculturally complex space, issues of racial and ethnic identities, languages spoken, and economic inequities, border pedagogies resist power and privilege that plays out when diverse $\mathrm{K}-12$ student populations and their families interact with predominantly White monocultural teachers as well as bilingual teachers socialized into dominant modes of thought reflected in classroom pedagogies (Halcón, 2001; Necochea \& Cline, 2005). Third, when the fluidity of the border with cultural flows and exchanges encounters the rigidity of dominant educational discourses reflected in policies and attitudes such as the English-only movement, border pedagogies enact critical multicultural classroom practices rather than enforcing monolingualism and cultural assimilation (Reyes \& Garza, 2005). Fourth, border pedagogies are reflected in parent-teacher partnerships for creating school curriculum, classroom practices, and teacher knowledge framed around local history, culture and language of students, parents, and communities (Cline \& Necochea, 2006).

\section{Critical Research Methodology}

The qualitative methodology for this study is positioned within critical research. According to Merriam (2009), critical research, like other forms of qualitative research, is interpretive as researchers explore a phenomenon in which participants make meaning of the world. However, unlike basic qualitative studies, critical research seeks not just to explore and 
understand but to examine, challenge, and transform participants' perceptions of the self and how they interact with the cultural other. Thus, this research examined:

1. How do teachers at the U.S.-Mexico border create opportunities for parental involvement to support student learning?

2. How do teachers enact and support complex multicultural border pedagogies that include the knowledges and experiences of students from binational, bilingual and bicultural communities?

\section{Background of the Study}

Approved by IRB, this study was conducted by an education faculty and a graduate research assistant at a bilingual public university in the U.S. located at the U.S.-Mexico border. The student population at the university is predominantly bilingual, consisting of students who self-identify as Mexican origin, Hispanic, Mexican, Latin American, and Central American. Students who identify as monolingual and White or Caucasian American or simply American are in the minority. A fraction of the bilingual student population is transnational and commutes across the bridge from Mexico on a daily basis to attend college in the U.S. Besides undergraduate teacher education students, the College of Education serves a large population of school districts through the master's program in Reading, ESL, and Bilingual Education and the Educational Leadership program at the doctoral level. The local school district serves predominantly bilingual Spanish communities identified as being 98.75\% Latino/Hispanic, while the rest of the student populations consist of $0.96 \%$ White, $0.07 \%$ Black, $0.2 \%$ Asian/Pacific Islander, and $0.01 \%$ American Indian/Alaska Native (National Council on Teacher Quality, 2014).

\section{Participants}

Selection of participants was based on non-probability sampling where individuals were selected because they were available, convenient, and represented some characteristic the researcher wanted to investigate (Creswell, 2005). An invitation to participate in the study was sent at the end of spring 2014 to in-service teachers enrolled in a master's course on bilingual education offered at a public university at the U.S.-Mexico border. The program provides students with knowledge of the history and research in the field of ESL and how to apply it to improve teaching and learning for EBs. In addition, students reflect upon the importance of advocacy, professional development, and collaboration with students' families and communities.

Sixteen in-service teachers agreed to participate in the study. All participants worked in dual language, bilingual, or ESL programs in school districts as teachers or language specialists serving predominantly EBs from either side of the border. Thirteen participants self-identified as Hispanic, were bilingual, and grew up at the border; two identified as Anglo, from New Jersey and North Carolina and had a working level of bilingual proficiency; one participant was Filipino with fluency in English and Filipino and low level fluency in Spanish.

\section{Data Collection}

In keeping with critical research, two sets of qualitative data were collected at the end of the spring 2015 and during the summer of 2015. First, data were collected in the form of individual interviews with participants. Two interview protocols were used for semi-structured interviews at the end of summer 2015 and lasted for one hour each. Individual interviewing allowed for in-depth exploration of participants' perceptions of the importance of parental 
involvement and advocacy for emergent bilingual students and their families. In the second set of data, artifacts and proposals were collected from a course project on border pedagogies that required participants to investigate and analyze the educational experiences of EBs in the school where they taught and the communities in which the EBs resided. In this project, participants reflected on the initiatives they had undertaken to involve parents in school curricula, selected critical issues in bilingual education in the context of the border, drafted a cultural advocacy pedagogy plan which would deepen parent-teacher partnerships, and assisted with improving the educational experience of EBs. At the end of the course project, participants compiled their findings in a final report and shared their border pedagogies with the rest of the class. To assure confidentiality, pseudonyms have been used for all participants, and participants were made aware that they could withdraw from the study at any point in the research.

\section{Data Analysis}

In the study, analysis was an ongoing and emerging process. Merriam's (2009) six analytical steps were followed to make sense of the data. The six steps of analysis are: searching for categories and themes, linking themes to propositions in the literature, searching for themes aligned with the conceptual framework, interpreting data, checking for trustworthiness of data and analysis, and reporting the findings. Accordingly, I categorized data from artifacts taken from interviews and course projects; sorted themes that supported propositions from the literature and conceptual framework; compared themes across data including cross-checking themes with a research assistant and conducting a member check; interpreted the data; and conducted a member-check to verify interpretations of data.

In addition, interview data were transcribed and a database for each interview was created. In the next step, data were divided into meaningful chunks of information and then sorted into thematic groupings. Interviews and documents were analyzed following the steps of interpretational analysis (Merriam, 2009). For trustworthiness within the study, I conducted a member check by sending transcripts of the interviews and subsequent analysis to the interviewees for comments and feedback. The researcher (the author) and the research assistant worked independently from each other and did a crosscheck of both sets of data analyses to assure reliability of the findings.

\section{Findings from the Study}

In spite of evidence that strong parent-teacher partnerships contribute to empowering schools, teachers, students, parents, and the wider community, findings from this study reveal meaningful partnerships other than school protocol between parents and teachers at the U.S.Mexico border is not a common phenomenon and gaps continue to persist. In agreement with existing research, some of the general factors contributing to the gap emerge from cultural, linguistic, and socioeconomic differences between teachers, even those who are bilingual with Spanish as their home language and diverse families leading to assumptions and beliefs on both sides. More specifically, in the context of this study, gaps persisted due to differences in perspectives, expectation of schooling, and communication between schools and parents.

Findings support current literature indicating that schooling experiences of Latino/a, Hispanic, and transnational students at the U.S.-Mexico border are affected by the diversity among students and their families; ongoing cultural exchanges and movement across borders; students' bicultural and bilingual status within schools that privilege monolingual standards 
reflected in educational policy; teachers' beliefs about bilingual students and how this translates into classroom practice; classroom practice guided by deficit theories; lack of ongoing professional development for monolingual and bilingual teachers on how to develop border pedagogies that use cultural knowledge and literacy practices of emergent bilingual students; multiple challenges students and diverse families encounter while adapting to a new culture, language, and school system; and gaps between schools and families in terms of communication patterns, expectations of teachers' and parental roles in the educational process, and support for teachers as well as resources for Spanish-speaking parents.

Aligning with advocates of border pedagogies, findings from this study evidenced instructional practice responsive to emergent bilingual students' cultures, languages, and transnational experiences with particular emphasis on building parent-teacher partnerships is a move toward educational equity with power to transform the schooling experiences of students at the U.S.-Mexico border. Rethinking their own classroom roles, in-service teachers who developed border pedagogies saw themselves as reflective practitioners, critiqued their own deficit assumptions, and were able to engage parents in school activities and viewed parentteacher partnerships as critical to effective instructional practice and student success. Teachers who viewed themselves as facilitators rather than the authority in the classroom validated the contribution of parents toward their children's education. Rather than buy into the dominant discourse of deficit perspectives about Spanish-speaking transnational students at the U.S.Mexico border or assume that diverse families whose first language is Spanish do not take interest in their children's schooling, in-service teachers who were open to developing pedagogies mindful of the bicultural and bilingual needs of the border actually took the curricula initiative to build strong parent-teacher partnerships and school-home collaborations.

In response to the changing diversity among families, findings showed that ongoing professional development through teacher education programs has the potential to empower and equip in-service teachers with the tools for developing new pedagogical frameworks that engage parents and teachers as partners in designing, implementing, and evaluating curricula attentive to the academic and social needs of a bilingual and bicultural geographical, historical, and transnational space constituting the U.S.-Mexico border. Findings indicate that border pedagogies informed the work of transforming relationships among classroom teaching, the production of student and teacher knowledge, and social relations of schools and teachers with parents and the wider community. Moreover, when gaps in communication between parents and teachers existed or school communication protocols were limited, border pedagogies provided instructional support for guiding teachers to think and talk about the bicultural linguistic needs of emergent bilingual students from diverse families, build parent-teacher partnerships through instructional changes, and create initiatives for active parental participation in their children's schooling. Findings revealed that when teachers were active participants and reflective practitioners, they considered parental engagement as critical to effective instructional practice and building their curricula accordingly.

Specifically, analysis of data revealed four key thematic findings: Communication tools for parental involvement; teacher initiatives for parental participation in curricula processes; school activities for parental involvement; and, parent-teacher literacy partnerships. In what follows, thematic extracts of data analysis highlight findings of teacher pedagogies and school practices with a focus on parent-teacher partnerships in relation to bilingual and bicultural teaching and learning. The selection of data extracts, thematic analysis, and subsequent findings were guided by their solid grounding in the enactment of border pedagogy as instructional 
practice for the success of emergent bilingual students. Each of the themes below illus trates how border pedagogy-centered perspectives provokes self-critique and informs reflective practice of in-service teachers.

\section{Theme One: Communication Systems for Parental Involvement}

Detailed study of both data sets evidenced there are several systems in place for parentteacher communication; however, there were several gaps in communication practices as well. Most of the teachers reported that the most common school communication system is through fliers the office sent home every day or as important events dates approached. Bilingual Middle school teacher Mona reported:

The most common methods of communications that are in place for the school to reach parents/guardians is mass communication via phone and parent flyers only. There is no system in place for parents/guardians to reach the school unless they call or come to the site.

Similarly, a high school teacher Oliver, who is bilingual, explained the different methods of communication used at his school:

Activities, important dates, events, and the like are communicated by the school through a series of methods such as phone messages/alerts; letters sent to parents via the mail or through the students as well as information placed in the ISD website.

An elementary teacher, Junita, stated:

We have email and call-out systems in place for general school announcements. These announcements go out in English and Spanish. The call-out system also generates an email to everyone who has an email address in the student database. Parents can call the school. School wide events or general school procedural/safety announcements are sent home as flyers. Parents can also email the teacher. They are also able to come up and request to talk with the teacher. Most of us teachers take 5 or 10 minutes of the conference period or lunch to at least chat with the parent and set up a time to meet later. We also try to communicate in Spanish, if necessary.

One of the bilingual elementary teachers interviewed, Cary, stated:

I communicate with parents about updates on grades, missing work, classroom performance both, negative and positive, and about important events. For example, "Meet the Teacher Night" by phone calls and emails to those who have an account. I also send letters to parents through the students and organize person-to-person conferences to discuss different issues.

Most of the topics of communication with parents discussed by all interviewees were around students' behavior, students' performance, or school events such as parent conferences. For example, Anna notes:

Every Friday, most teachers send home a yellow "Friday folder" with notes about the students' academic and behavioral performance for the week. Parents are to read, sign and return. Included are also various flyers about school/community events that are coming up.

The above data indicate most teachers depend on traditional communication that does not require building a close professional relationship with parents. Most of the teachers make phone calls for parent meetings, send information by email in keeping with school policy, or expect parents to access information on the school and district website. As noted in the literature, bilingual participants had the same response to parental involvement as monolingual speakers 
and spoke about parental involvement as a school policy rather than building long-term relationships and partnerships according to the needs of students from border communities. Findings showed most teachers did not consider cultural or linguistic responsiveness as part of their pedagogies. None of the participants mentioned the barriers parents might encounter in terms of not having access to phones, emails or computer usage. Findings indicate teachers spoke of communication as unidirectional with schools sending information and parents responding to this information, rather than as two way interaction between equal partners and stakeholders.

Two critical differences emerged from the above data between middle and secondary teachers and elementary teachers. First, middle and secondary teachers restricted their communication to phone, email or school flyers with no reference to using bilingualism as a classroom resource or for communicating with parents. Elementary teachers, on the other hand, reached out to individual parents and had set a time aside each day to speak directly with parents. Second, elementary teachers were willing to communicate with parents in English and Spanish.

\section{Theme Two: Teacher Initiatives for Parental Participation in Curricula Processes}

According to the reviewed literature, parental participation in curricula processes and school events contribute to school-parent partnerships and impact academic outcomes in positive ways. Data revealed differing attitudes of teachers toward engaging parents in curricula processes that ranged from resistant attitudes toward parental involvement to active initiatives for engaging directly with parents. A secondary school teacher, Peony, resisted the place of culturally responsive pedagogy in her classroom, saying:

Parents do not influence my teaching since I do not have time to talk to parents or discover their funds of knowledge to incorporate into my curriculum.

In contrast, another high school teacher, Oliver, interacted with parents and gained funds of knowledge, which helped him develop culturally responsive pedagogies:

My conversations with the parents gave me a glimpse of the student's home life, I also got to look into the family's funds of knowledge and get a better insight into parenting and communicating styles of the parents whose children I teach. The conversations helped me develop a better understanding of children in my class.

A middle school teacher, Natasha, explained her active initiative toward responding to parents and students:

If parents inform me of some condition/challenge that their child has then I make accommodations for their child within the classroom. For example, I use to have a child that would get stressed out because I gave him homework. So I started doing the homework with him during lunch. It really helped the child be more at ease.

An elementary teacher, Lima, notes:

I started the year by asking parents to write a letter about their child. I gave them specific questions or talking points to consider, but encouraged them to just share with me anything they wanted me to know about their child, their culture, interests to help me understand/get to know their child better and improve my own knowledge of students. I didn't get letters back from every parent, but the ones that did write were informative. The above data reflects the literature on the subtractive education of EBs (Valenzuela, 1999) and the critical need for preparing teachers with knowledge of border pedagogies that build upon school and parent partnerships to improve academic outcomes of students at the U.S.Mexico border. As seen from Peony, her deficit perspective and unidirectional approach to parental involvement served as a barrier to parent-teacher partnerships. As documented in the 
literature, educators invested in the dominant discourse view culturally and linguistically diverse students and their families as not worthy of curriculum time or as an intrusion in their teaching. On the other hand, Lima is aware of the diverse knowledge that students bring into the class and is willing to seek this knowledge as helpful in developing culturally responsive pedagogies.

As seen from the theoretical framework, the dynamics of power between teachers with cultural capital and parents who lack educational, linguistic, or social capital results in a wide gap that alienates parents rather than includes them in curricula decisions. Rather than include families in curricula processes, teacher Peony represents deficit attitudes toward parental involvement noted in the literature and shows a lack of reflective pedagogical skills in supporting parental involvement. On the other hand, Oliver, Natasha, and Lima are cognizant of context and culture and willing to include knowledge of students and parents to develop curricula.

\section{Theme Three: School-driven Activities for Parental Involvement}

According to the findings, most teachers at the secondary level engaged in parent-teacher partnerships when directed by school programs and events. A teacher, Oliver, explains some of the opportunities for parental involvement that the school organized:

The school has also organized literacy nights to increase social capital of the parents/families so they create the most conducive home environment for students to be successful. The school provides assistance and resources on helping students with homework by hiring its own teachers for tutorials. Moreover, in our department, we facilitate a strong partnership with students' families by having a Math night with project presentations.

Working for a school without resources, an elementary teacher, Effie, reports on the challenge faced by EBs and parents in completing homework in English:

In regards to homework, the school has no official way to provide assistance and resources on helping students with homework. However, the library is always open after school for parents and teachers, and our librarian, if asked, would be more than happy to help any student with homework.

In addition, some teachers at the elementary level discussed special services and activities for parents offered by the parent liaisons; however, teachers were not involved in these services and events. Fiona explains:

The campus has a parent liaison that is in charge of all parental activities. She provides parents learning academies where parents can come and learn about the different services available to them. She also arranges/sets up to have English classes, core curriculum classes, crafting classes, preventing child abuse classes, etc. The most attended ones are the crafting classes. Parents and grandparents are the ones that attend these sessions.

Several teachers shared information about special language services offered at their schools at both levels, elementary and secondary. An elementary teacher, Didi says:

Through the parent center, my school district provides adult education classes on English, computers, etc. to parents. The biggest attendance, so far, is on the language courses. Parents from different campuses show up to take the English classes.

Another teacher, Beth also discussed the type of services at her school including literacy

nights that also seems to be a recurring theme of the services offered across schools:

Nutrition and ESL classes are the two classes most attended and the same group of Latino mothers usually attend them each year. We also have Family Library Nights when 
each grade level organizes and hosts one of these throughout the year. These nights have a broad focus: music performance with music teachers, read-alouds or author talks, technology, among others and brings parents closer to schools.

The data show some schools organize special events that teachers view as opportunities for parental and community engagements. Secondary teacher Fiona, explains:

At my campus we have the AVID teacher who is also a city commissioner. He is the one in charge to partnering up with the community. The importance of having the community as part of the campus is that it provides information about services to the parents and students around the community and surrounding areas.

Similarly, teachers at the elementary level reported activities in which the teachers at the school or other personnel advocate for the families. One of the teachers, Gina, provided an example of the wide range of services provided at her school:

The Communities in Schools Program's coordinator at my school has a strong partnership with parents and the community at large. This program offers services in parent/child activities and parenting skills training. In addition, they offer Walk-In services for support, guidance, and linkages to community resources such as clinic referrals for medical and emotional needs, school uniforms and supplies, financial assistance with rent and utilities, and connecting them with local churches/outreach centers that provide similar support, especially around the Holidays for all parents in need.

As seen from the above data, even though teachers may not initiate parent-teacher partnerships, they endorse partnered school and community events and see the value in including parents in school programs which has direct implications for EBs' education. Teachers benefit from the partnership as they acquire the knowledge and skills to work with EBs, develop pedagogies that are culturally relevant in the unique context of the border, and connect with the local community. Parental involvement through school events such as Family and Library Nights and language services help parents to feel included in school curricula and participate more fully in their children's education.

\section{Theme Four: Parent-teacher Pedagogical Partnerships}

A better understanding of parent-teacher partnerships emerged from teachers' advocacy projects on border pedagogies as part of their graduate coursework. After documenting parentteacher communication tools, teacher initiative in engaging parents, and school events and activities for parental involvement, teachers in this study reflected on the gaps in their own knowledge and skills and created a detailed plan for addressing these gaps by developing a plan for strengthening parent-teacher partnerships which they would implement in their classrooms.

One of the teachers, Anna, proposed a project for engaging parents to support their children's mathematical knowledge acquisition:

Teachers will communicate to parents the knowledge and skill their children lack and together they will coordinate dates and times for make and take sessions on skills required for students to become fluent in problem solving that involves finding the sum, difference, product, and/or quotient.

According to the literature, and my own professional experience working with teachers in schools, the feelings of many students and parents who feel alienated from schools are further compounded by bullying on school campuses. Schools at the border consist of predominantly Hispanic populations, and bullying emerges from the power dynamics between long-term EBs 
who assume a sense of superiority in their cultural assimilation, and recent immigrants who are adjusting to the new cultural environment of school and society. Concerned about bullying, a middle school teacher, Mona, proposed a project that would address intracultural bullying: Many students are bullied in school and I proposed scheduling open house during the first week in October in combination with National Bullying Prevention Month. Spearheaded by school counselors, this event would involve students talking about their experiences with bullying, as well as teachers, parents, local community members, and government agencies such as law enforcement participating to raise awareness of bullying prevention and to make new students feel safe in our school.

As parental and teacher expectations differ, a teacher, Kyle, proposed a plan focused on providing homework support which would be bilingual in content and pedagogy:

The "Ayuda con la Tarea/Help with Homework" program will consist of 6 meetings throughout the year. A meeting will be set up for EBs' parents once every six weeks and would be conducted in the parents' first language (Spanish). The goal is to provide parents of EBs with information and materials about the topics studied during each grading period, and teacher expectations about homework. This will also help teachers to learn more about parents and their needs and concerns.

The following plan was developed by India, one of the teachers who focused on developing pedagogies around culturally and linguistically relevant content:

Now I realize that at the border, reading has to be relevant to students and parents. The advocacy project will consist of several sessions where the book Esperanza Rising will be read aloud by different teachers to the students and families. They will have a choice of listening to the book in Spanish or English. Since it is a story of immigration, family and persistence many EB's and their family will connect with the story at a personal level. After the read aloud sessions, the families will be assigned part of a wall at the school. Each family will be responsible for painting a mural that summarizes the main ideas and supporting details of the book and represent their own unique border experiences that might be similar to the novel. Local artists will be invited to assist the parents with their artwork.

As illustrated by the above analysis of data, several critical issues emerged from the advocacy project. First, after deliberate discussions in the classroom, interviews with students, and their own reflections on the needs of EBs, parent-teacher partnerships, and their role in fostering partnership, most of the teachers recognized the need for border pedagogies that were unique to their own teaching contexts at the U.S.-Mexico border. Second, having identified the gaps to parent-teacher partnerships, teachers were passionate about making changes to their own pedagogies. Third, although their previous attitude was to blame parents or protect their school time, teachers were more willing to take initiative in engaging parents, getting to know their communities, and working in partnership for the success of EBs. Finally, many of the teachers recognized that project engagement was an opportunity for them to know the cultural diversity and home literacy practices of students and parents and develop border pedagogies that validated biculturalism, bilingualism, and binationalism as assets to teaching and learning.

\section{Discussion and Implications for Emergent Bilingual Education}

This study contributes to scholarship at the intersection of bilingual education and border pedagogy by advocating parent-teacher partnership as key to supporting the academic 
performance of EBs. Considering parent-teacher partnerships as critical to the success of emergent bilingual education, this study highlights three key issues: a) gaps between parents and teachers, b) evidence of why some of these gaps persist, and c) border pedagogies as resources and strategies for closing these gaps. Exploration of parent-teacher interactions underscores the complexities and intersections of border cultures, teachers' attitudes toward bilingualism, and barriers to parent-teacher partnerships. The study reinforces the need to further examine the challenges teachers encounter in developing a bicultural, bilingual, binational border mindset that includes knowledge of students' home cultures and how to include diverse knowledges in making curricula decisions. Findings indicate certified in-service teachers were underprepared to deal with the complexities of border regions and needed ongoing professional development to become more reflective and attend to the academic, cultural and linguistic needs of diverse students at the border.

This study informs teacher preparation, professional development for teachers, and future teachers in ways that inform their understanding of the experiences of diversity at the border and across multicultural school contexts. Teacher education programs play an important role in developing culturally and linguistically responsive teachers who are able to examine their own biases evidenced in their teaching practice and are willing to change their responses to diversity so that EBs have equal opportunities for academic success. This shift in teachers' level of parentteacher partnerships, with support from teacher education coursework, helps teacher educators and their students to contextualize educational experiences and gain a better understanding of themselves, their students, and teaching in a border region. Developing border pedagogies as part of coursework, teachers who are bilingual themselves are able to reflect on their deficit perspectives toward bilingualism and biculturalism and question their own cultural knowledge and biases within them.

Professional development through border pedagogies in teacher education programs contributes toward helping teachers to connect their classroom experiences to theoretical frameworks and hands-on experiential learning. When teachers acquire cultural knowledge of the communities they work in and develop pedagogies unique to the border, they are addressing challenges posed by complex intersections of cultural differences in terms of race, ethnicity, class, language, national origin and culture. Border pedagogies provide teachers with a theoretical framework for recognizing sociocultural and political dynamics in the classroom and grounding their philosophies in the educational needs of diverse communities they teach. When teachers see themselves as border pedagogy educators they reflect on their own knowledge, perceptions, and attitudes and develop dispositions that support strong parent-teacher partnerships with a commitment to communities at the border.

One of the limitations of the study is the small sample size. Follow-up studies might be conducted with a larger group of participants, as well as research conducted on how participants implemented their border pedagogies. In addition, based on findings from this study, further research is needed on building school capacity to understand the needs of EBs and their families through long-term community partnerships. Recommendations are also made for teacher education programs to develop a practice-focused and project-based curriculum for in-service teachers in which coursework connects theory to classroom practice based on the academic and cultural needs of the community. Project-based coursework using border pedagogies might include curricula input from parents, shared instructional practices, cultural knowledge of teachers, students, and parents that reflects diversity of cultures and languages. These pedagogies might include but are not limited to having two-way communication systems in place rather than 
unidirectional, offering parental guidance and support for effective learning opportunities at home, building on funds of knowledge of parents and developing partnerships with the community to recognize the cultural knowledge of students and their families.

Findings from this study suggest a pedagogical shift from teacher perspectives grounded in deficit notions of cultural and linguistic diversity and changing in-service teachers' pedagogies toward a more complex and contextual understanding of EBs and their families. Schools might create opportunities and develop programs that close the gap between teachers and parents and establish close and caring parent/teacher partnerships. In conclusion, border pedagogies that attend to the contextual need of diverse students, including emergent bilinguals, is made possible when teacher educators, in-service teachers, and future teachers work in close partnerships with parents, families and communities they serve. 


\section{References}

Arias, M. \& Morillo-Campbell, M. (2008). Promoting ELL parental involvement:

Challenges in contested times. Retrieved August 25, 2015, from http://epsl.asu.edu/epru/ documents/EPSL-080 1-250-EPRU.pdf

Ariza, E. N. W. (2010). Not for ESOL teachers: What every classroom teacher needs to know about the linguistically, culturally, and ethnically diverse student (2nd ed.). Boston, MA: Pearson.

Auerbach, S. (2007). Visioning parent engagement in urban schools. Journal of School Leadership, 17(6), 699-734.

Auerbach, S. (2009). Walking the walk: Portraits in leadership for family engagement in urban schools. School Community Journal, 19(1), 9-31.

Ballantyne, K. G., Sanderman, A. R., Levy, J. (2008). Educating English language learners: Building teacher capacity. Washington, DC: National Clearinghouse for English Language Acquisition. Available at http://www.ncela.gwu.edu/practice/mainstream_teachers.htm.

Bedolla, L. G. (2005). Fluid borders: Latino power, identity, and politics in Los Angeles. Berkeley, CA: University of California Press.

Bourdieu, P. (1986). The forms of social capital. In J.G. Richardson (Ed.). Handbook of theory and research for the sociology of education (pp. 241-58). New York: Greenwood.

Cline, Z. \& Necochea, J. (2006). Teacher dispositions for effective education in the borderlands. The Education Forum, 70, 268-281.

Cline, Z. \& Necochea, J. (2003). El poder de la voz: Un diálogo binacional. El Bordo: retos de frontera, 6(11), 15-38.

Coleman, J. S. \& Hoffer, T. (1987). Public and private high schools: The impact of communities. New York: Basic Books.

Creswell, J. W. (2005). Educational research: Planning, conducting, and evaluating quantitative and qualitative research (4th ed.). Boston, MA: Pearson.

Darling-Hammond, L., \& Bransford, J. (Eds.). (2005). Preparing teachers for a changing world: What teachers should be able to do. San Francisco, CA: Jossey-Bass.

de la Piedra, M.T. (2007). Making connections: Bilingual pre-service teacher's service-learning with Spanish-speaking parents living in the U.S/Mexico border. TABE Journal, 9(2), 98114. 
Epstein, J. L. (2001). School, family and community partnerships: Preparing educators and improving schools. Boulder, CO: Westview Press.

Estrada, B. (2006). The Border Pedagogy Initiative: An opportunity for growth and transformation. Hispanic Outlook, 34-36.

Gándara, P. (2011). Latinos, language, and segregation: Options for a more integrated future, in Frankenberg, E., \& DeBray, E. (Eds.). Integrating Schools in a Changing society: New policies and legal options for a multiracial generation. (pp. 265-278). University of North Carolina Press.

Gándara, P., Maxwell-Jolly, J. \& Driscoll, A. (2005). A Survey of California Teachers' Challenges, Experiences, and Professional Development Needs. The Center for the Future of Teaching and Learning. Santa Cruz, CA: Linguistic Minority Research Institute. http:/files.eric.ed.gov/fulltext/ED491701.pdf

Garcia, E., \& Cuellar, D. (2006). Who are these linguistically and culturally diverse students? Teachers College Record, 108, 2220-2246.

Garcia, O., Kleifgen, J., \& Falchi, L. (2008). From English language learners to emergent bilinguals. Research Review Series Monograph, Campaign for Educational Equity. New York, NY: Teachers College, Columbia University.

Garza, E. (2007). Becoming a border pedagogy educator: Rooting practice in paradox. Multicultural Education, 14(4), 1-6.

Guerrero, M. \& Farruggio, P. (2012). Neoliberal teacher preparation: Conceptualizing a response in the US borderlands. Education Inquiry, 3(4), 553-568.

Guerrero, M. \& Valadez, C. (2011) Fostering candidate Spanish language development. In Flores, B. B., Sheets, R. H., \& Clark, E. R. (Eds.) Preparing teachers for bilingual student populations: Educar para transformar. (pp.59-72). NY: Routledge.

Halcón, J. (2001). Mainstream Ideology and Literacy Instruction for Spanish-Speaking Children. In Reyes, M. de la Luz, \& Halcon, J. J. (Eds), The best for our children: Critical perspectives on literacy for Latino students (pp. 65-80). New York: Teachers College Press.

Houk, F. A. (2005). Supporting English Language Learners: A Guide for Teachers and Administrators. Portsmouth, NH: Heinemann.

Merriam, S. B. (1998). Qualitative research and case study applications in education. San Francisco: Jossey-Bass.

Merriam, S. B. (2009). Qualitative Research: A Guide to Design and Implementation, ( $3^{\text {rd }}$. ed). San Fransisco, California :Jossey-Bass. 
National Council on Teacher Quality. (2014). Teacher Prep Review. Washington, DC: NCTQ.

Necochea, J. \& Cline, Z. (2005). Borderland education and teacher education reform in California: Unfulfilled promises. Journal of Borderlands Studies, 20(1), 129-141.

Nieto, S. (2004). Affirming diversity: The sociopolitical context of multicultural education, (4th ed). New York: Pearson.

Reyes, M. de la Luz \& Garza, E. (2005). Teachers on the border: In their own words. Journal of Latinos in Education, 4(3), 120.

Reyes, M. de la Luz. (2005). Introduction to the special issue: Educational lives on the border. Journal of Latinos and Education, 4(3), 149-152.

Rodriguez, A., \& Mercuri, S. (2013). Rethinking bilingual teacher education in a USMexico border community. The Texas Forum of Teacher Education, 3, 72-86.

Romo, J. J. \& Chavez, R. H. J. (2006). Border Pedagogy: A Study of Preservice Teacher Transformation. The Educational Forum, 70, 142-153.

Ruiz-Soto, A., Hooker, S. \& Batalova, J. (2015). States and Districts with the Highest Number and Share of English Language Learners. Washington, D.C: Migration Policy Institute.

Shulman, L. (2005). Signature pedagogies in the professions. Daedalus, 134(3), 52-59.

Siwatu, K. (2007). Preservice Teachers' Culturally Responsive Teaching Self-Efficacy and Outcome Expectancy Beliefs. Teaching and Teacher Education: An International Journal of Research and Studies, 23(7). 1086-1101.

Sleeter, C. E. (2001). Preparing teachers for culturally diverse schools: Research and the overwhelming presence of Whiteness. Journal of Teacher Education, 52(2), 94-106.

Stanton-Salazar, R. D. (2004). Social capital among working-class minority students. In Gibson, M., Gándara, P., \& Koyama, J. P. (Eds.), School Connections: U.S. Mexican Youth, Peers, and School Achievement. (pp.18-38 ). New York: Teachers College Press, Columbia University.

Valenzuela, A. (1999). Subtractive schooling: US-Mexican youth and the politics of caring. Albany, New York: State University of New York Press.

Valdés, G. (1996). Con respeto: Bridging the differences between culturally diverse families and schools: An ethnographic portrait. New York: Teachers College Press.

Zong, J., \& Batalova, J. (2015). Frequently Requested Statistics on Immigrants and Immigration in the United States. The Online Journal of the Migration Policy Institute Report. 